\title{
Akurasi Pemeriksaan Biopsi Aspirasi Jarum Halus (BAJAH) dalam Diagnosis Keganasan Kelenjar Getah Bening Leher
}

\author{
Wiganda, Dimyati Achmad, Maman Abdurahman
}

\begin{abstract}
Abstrak
Pendahuluan : Teknik pemeriksaan biopsi aspirasi jarum halus (BAJAH) bersifat cepat, aman, dan kurang invasif untuk mendiagnosis keganasan pada kelenjar getah bening. Tujuan penelitian ini adalah untuk menilai akurasi, sensitivitas, spesifisitas, nilai ramal positif, dan nilai ramal negatif pemeriksaan BAJAH pada penderita limfadenopati koli yang berobat ke Subbagian Bedah Onkologi Kepala dan Leher Bagian Bedah RS Hasan Sadikin, Bandung (RSHS).

Metode : Penelitian ini merupakan uji diagnosis pemeriksaan BAJAH pada penderita dengan diagnosis klinis limfadenopati koli. Hasil pemeriksaan BAJAH dibandingkan dengan baku emas pemeriksaan histopatologis. Subjek penelitian adalah penderita yang berobat di Subbagian Bedah Onkologi Kepala dan Leher Bagian Bedah RSHS, dengan keluhan pembesaran kelenjar getah bening di leher. Penelitian ini telah mendapat persetujuan dari Komite Etik Penelitian Kesehatan Fakultas Kedokteran Universitas Padjadjaran (FKUNPAD)/RS Hasan Sadikin, Bandung. Selama penelitian yang dilakukan pada bulan Januari 2008 hingga April 2008 didapatkan 36 orang yang sesuai dengan kriteria inklusi, terdiri dari 16 orang laki-laki dan 20 orang perempuan, dengan rentang usia antara 14 tahun sampai dengan 87 tahun.

Hasil : Pada pemeriksaaan histopatologis didapatkan 12 orang menderita limfadenopati ganas, dan 24 orang dengan limfadenopati jinak. Pada pemeriksaan BAJAH didapatkan positif palsu 1 penderita, dan negatif palsu 1 penderita. Akurasi diagnosis pemeriksaan BAJAH adalah 94,4\%, sensitifitas $91,7 \%$, spesifisitas $95,8 \%$. Nilai ramal positif dan negatif dari metode pemeriksaan ini adalah 91,7\% dan $95,8 \%$.

Diskusi : Uji diagnosis BAJAH terhadap adanya keganasan pada limfadenopati koli memiliki akurasi 94,4\%, sensitivitas $91,7 \%$, spesifisitas $95,8 \%$, nilai ramal positif $91,7 \%$ dan nilai ramal negatif $95,8 \%$. Pemeriksaan BAJAH dapat digunakan secara rutin untuk mendiagnosis keganasan limfadenopati koli pada penderita yang menolak dilakukan biopsi terbuka.
\end{abstract}

Katakunci : akurasi, BAJAH, limfadenopati leher, sensitifitas, spesifisitas. (J I Bedah Indones. 2007; 35(2): 48-52)

\section{Diagnostic Accuracy of Fine Needle Aspiration Biopsy (FNAB) in Detecting Malignant Node Involments of The Neck Region}

\begin{abstract}
Introduction: The diagnosis of the malignant node involment is mostly based on open biopsy of histopathology, which is time consuming. Recently there has been simplier, and less invasive technique known as fine needle aspiration biopsy (FNAB). The aim of this study is to determine the accurancy, sensitivity, specificity, and predictive values of FNAB for diagnosis of modal malignancy at the neck region.

Methods : Through this diagnostic, samples were collected from patients who visit to the Oncology Division (Head and Neck) of Surgery Department of Hasan Sadikin Hospital Bandung from January 2008 until April 2008. FNAB examination were performed to patients who clinically diagnosed as lymphadenopathy of the neck region. The FNAB results were then compared to histopathological examination results as the gold standard.

Results : Sixteen males and 20 females, aged between 14-87 years were enrolled. Twelve revealed malignant according to histopathologic examination while the other 24 showed no evidence of malignancy. Among the 12 with malignancy by the histopathological examination, 1 was negative in malignancy according to FNAB. The accuracy of FNAB examination as a diagnostic method in this study was $94.4 \%$, whilst the sensitivity was $91.7 \%$. Among the 24 negatif malignancies by FNAB, 1 of them showed positif malignancy by histopathological examination. The specificity of FNAB examination was $95.8 \%$. Positive and negative predictive value was $91.7 \%$ and $95.8 \%$ respectively.

Discussions : The accuracy of FNAB was 94.4\%, sensitivity 91.7\%, specificity 95.8\%. Fine needle aspiration biopsy could be recommended for diagnosis of malignant node of the neck region.
\end{abstract}

Keywords: accuracy, fine needle asipiration biopsy, neck lymphadenopathy, sensitivity, specificity. (J I Bedah Indones. 2007; 35(2): 48-52)

Bagian Ilmu Bedah Fakultas Kedokteran

Universitas Padjadjaran/RS Hasan Sadikin, Bandung 


\section{PENDAHULUAN}

Pembesaran kelenjar getah bening (limfadenopati) dapat disebabkan pula oleh suatu infeksi yang akut maupun kronik, di samping itu dapat disebabkan oleh suatu keganasan limfoid, metastasis suatu keganasan, serta hiperplasia reaktif dari suatu penyakit sistemik..$^{1-3}$ Insidens keganasan pada daerah kepala dan leher adalah 7\% dari semua kasus keganasan. Delapan puluh lima persen tumor di leher (di luar tiroid) pada orang dewasa adalah neoplasma ganas dan $15 \%$ disebabkan oleh inflamasi/kongenital. Delapan puluh lima persen neoplasma ganas tersebut merupakan suatu metastasis. ${ }^{4,5}$

Biopsi terbuka kelenjar getah bening merupakan salah satu cara yang penting untuk diagnosis, akan tetapi tindakan biopsi terbuka lebih invasif, mempunyai risiko memermudah terjadinya penyebaran dan disertai morbiditas. ${ }^{6}$ Pemeriksaan biopsi aspirasi jarum halus (BAJAH) pada kasus limfadenopati koli merupakan pemeriksaan yang kurang invasif, aman, dan cepat dibandingkan pemeriksaan histopatologis dengan biopsi terbuka. Pemeriksaan BAJAH hanya menyebabkan trauma kecil dan tidak mahal. ${ }^{7}$ Dari berbagai kepustakaan pemeriksaan BAJAH mempunyai akurasi diagnosis malignansi yang bervariasi. ${ }^{8}$ Akurasi pemeriksaan BAJAH tergantung pada ketepatan pengambilan sampel dan pengalaman ahli sitologi. ${ }^{8}$ Diagnosis keganasan pada limfadenopati koli dengan pemeriksaan histopatologis ditegakkan berdasarkan gambaran morfologis sel, komposisi sel, dan perubahan struktur jaringan. Pada pemeriksaan BAJAH dengan hanya melihat gambaran komposisi sel dan morfologi sel diagnosis keganasan dapat juga ditegakkan pada limfadenopati koli. ${ }^{8}$

\section{METODE}

Penelitian ini dirancang secara cross sectional study. Pengambilan sampel dilakukan terhadap penderita dengan keluhan pembesaran kelenjar getah bening didiagnosis klinis di Subbagian Bedah Onkologi Kepala dan Leher Bagian, Bagian Ilmu Bedah FKUNPAD/ RSHS, Bandung, terhitung mulai Januari 2008 sampai dengan April 2008

Hasil pemeriksaan BAJAH dibanding dengan baku emas diagnosis pemeriksaan histopatologis dengan biopsi terbuka.

Pengambilan sampel BAJAH dan pemeriksaan sitologi dilakukan oleh seorang spesialis patologi anatomi sedangkan pengambilan biopsi terbuka dilakukan oleh residen bedah tingkat III/IV dan pemeriksaan histopatologi dilakukan spesialis patologi anatomi yang berbeda. Pengambilan sampel biopsi terbuka dilakukan pada benjolan yang sama dengan tempat pengambilan sampel BAJAH. Pengambilan sampel BAJAH dilakukan pada beberapa tempat yang dicurigai, dibuat minimal 2 buah preparat sitologi. Preparat sitologi difiksasi dengan larutan alkohol 95\% dan dilakukan pewarnaan metoda Papanicolaou.

Terdapat 38 penderita yang berobat ke Poliklinik Subbagian Bedah Onkologi Kepala dan Leher Bagian RS
Hasan Sadikin dengan keluhan pembesaran kelenjar getah bening di leher. Penderita yang sesuai dengan kriteria inklusi terdapat sebanyak 36 penderita.

Kriteria inklusi adalah penderita laki-laki atau perempuan berumur sama dengan atau lebih dari 14 tahun yang berobat di Poliklinik Subbagian Bedah Onkologi Kepala dan Leher Bagian RS Hasan Sadikin dengan diagnosis klinis limfadenopati koli.

Kriteria eksklusi penderita dengan limfadenopati koli yang sebelumnya sudah mendapatkan terapi antibiotik atau telah dilakukan biopsi atau radiasi, sampel tidak adekuat dan subsrat dari kelenjar getah bening leher.

Data dikumpulkan, ditabulasi dalam tabel $2 \times 2$, dihitung angka akurasi, sensitifitas, spesifisitas, nilai ramal positif, nilai ramal negatif, dan dilakukan analisis. Uji statisik adalah uji Z.

\section{HASIL}

Selama periode Januari 2008 hingga April 2008 didapatkan 38 penderita yang berobat ke Poliklinik di Poliklinik Subbagian Bedah Onkologi Kepala dan Leher Bagian RS Hasan Sadikin dengan keluhan pembesaran kelenjar getah bening di leher. Penderita yang eligible sebanyak 36 penderita, terdiri dari 16 penderita $(44,4 \%)$ laki-laki dan 20 penderita $(55,6 \%)$ perempuan, dengan rentang usia antara 14 tahun sampai dengan 87 tahun. Dua penderita diekslusi karena satu penderita pemeriksaan BAJAH tidak dapat ditentukan jinak atau ganas, dan menolak untuk dilakukan BAJAH ulang, dan 1 penderita diketahui substratnya bukan berasal dari kelenjar getah bening.

Dari hasil pemeriksaaan histopatologi didapatkan $10(27,8 \%)$ penderita dengan metastasis karsinoma kelenjar getah bening, $1(2,8 \%)$ penderita Hodgkin limfoma, $1(2,8 \%)$ penderita non Hodgkin limfoma, 3(8,3\%) penderita hiperplasia reaktif, $15(38 \%)$ penderita limfadenitis TB, 4(11,1\%) penderita limfadenitis nonspesifik, 2(5,5\%) penderita dengan lesi granulomatous, sedangkan dari pemeriksaan BAJAH didapatkan $10(27,8 \%)$ penderita dengan metastasis karsinoma kelenjar getah bening, 1(2,8\%) penderita Hodgkin limfoma, $4(11,1 \%)$ penderita hiperplasia reaktif, $15(38 \%)$ penderita limfadenitis TB, $3(8,3 \%)$ penderita limfadenitis kronik nonspesifik, $1(2,8 \%)$ penderita non Hodgkin limfoma, dan 2(5,5\%) penderita lesi granulomatous (Tabel 1).

Tabel 1. Hasil pemeriksaan histopatologi dan pemeriksaan BAJAH pada penderita limfadenopati koli

\begin{tabular}{|c|c|c|c|c|c|}
\hline \multirow{3}{*}{ Variabel } & \multirow{3}{*}{$\mathrm{n}$} & \multicolumn{4}{|c|}{ Histopatologi } \\
\hline & & \multicolumn{2}{|c|}{ Ganas } & \multicolumn{2}{|c|}{ Tidak ganas } \\
\hline & & $\mathrm{n}$ & $\%$ & $\mathrm{n}$ & $\%$ \\
\hline Ganas BAJAH & 12 & 11 & 30,6 & 1 & 2,8 \\
\hline Tidak ganas & 24 & 1 & 2,8 & 23 & 63,4 \\
\hline Jumlah & 36 & 12 & 33,4 & 24 & 66,2 \\
\hline
\end{tabular}


Berdasarkan tabulasi silang pada Tabel 1 dapat dihitung akurasi, sensitifitas, spesifisitas, nilai ramal positif, dan nilai ramal negatif. Hasil pemeriksaan dari 36 penderita dengan limfadenopati koli pada penelitian yang ganas adalah $11(30,6 \%)$ penderita dan yang jinak $23(63,4 \%)$ penderita, sehingga akurasi pemeriksaan BAJAH adalah 94,4\%.

Dari penelitian ini didapatkan $11(30,6 \%)$ penderita menunjukkan hasil pemeriksaan BAJAH adalah ganas dan $1(2,8 \%)$ penderita bukan keganasan tetapi pada pemeriksaan histopatologis menunjukkan hasil ganas (negatif palsu). Dengan demikian sensitifitas diagnosis keganasan pada limfadenopati koli dengan pemeriksaan BAJAH adalah 91,7\%.

Dari hasil penelitian ini didapatkan 23 penderita tidak sama, baik dari hasil pemeriksaan BAJAH maupun biopsi terbuka dan 1 penderita yang dinyatakan tidak ganas dengan pemeriksaan BAJAH, ternyata dengan pemeriksaan histopatologi menunjukkan hasil ganas (negatif palsu). Dengan demikian spesifisitas diagnostik keganasan pada limfadenopati koli dengan pemeriksaan BAJAH adalah 95,8\%

Dari hasil data tersebut dapat ditentukan bahwa pemeriksaan diagnosis BAJAH mempunyai nilai ramal positif 91,7\% dan nilai ramal negatif $95,8 \%$.

\section{DISKUSI}

Hasil penelitian ini menunjukkan bahwa nilai akurasi, sensitifitas, dan spesifisitas diagnosis pemeriksaan BAJAH terhadap keganasan pada limfadenopati koli adalah tinggi masing-masing 94,4\%, 91,7\%, dan 95,8\% (koefisien agreement $(\hat{K})=0,876)$. Hasil tersebut hampir sama dengan penelitian prospektif Muhammad Javaid dkk. tahun 2006 yang meneliti pemeriksaan BAJAH pada keganasan limfadenopati koli yakni akurasi $95,23 \%$, sensitifitas $95,8 \%$, spesifisitas $94,44 \%$, nilai ramal positif $95,85 \%$, dan nilai ramal negatif sebesar $94,44 \% .{ }^{18}$ Sedangkan Nada A dkk. mendapatkan akurasi $89,6 \% .{ }^{9}$ Penelitian yang dilakukan oleh Lee Zimmer dengan review terhadap 567 penderita dengan benjolan di leher didapatkan angka sensitifitas antara $85-90 \%$ positif palsu dan negatif palsu $10-15 \% .{ }^{10}$ Dari nilai sensitifitas yang tinggi tersebut pemeriksaan BAJAH dapat dipakai untuk mendiagnosis adanya keganasan pada limfadenopati koli.

Dari nilai ramal positif didapatkan hasil yang tinggi yakni sebesar $91,7 \%$ dan nilai ramal negatif hasilnya $95,8 \%$ artinya bahwa apabilahasil pemeriksaan BAJAH positif keganasan maka kita bisa menduga besar kemungkinannya penderita tersebut menderita keganasan pada limfadenopati koli, dan apabila hasil pemeriksaan BAJAH negatif keganasan berarti sebaliknya.

Dari hasil perhitungan diketahui didapatkan pretest probability atau prevalens sebesar $33,33 \%$ dan post-test probability sebesar $91,17 \%$ (untuk cara perhitungan dapat dilihat di Tabel 2). Ada perbedaan antara pretest probability dan post-test probability yang besar yaitu 57,84\%, hal ini menggambarkan besarnya kemungkinan penderita yang

Tabel 2. Perhitungan uji diagnostik

\begin{tabular}{|c|c|c|c|}
\hline Akurasi & $=\frac{a+d}{a+b+c+d} \times 100 \%=$ & $\frac{34}{36} \times 100 \%=$ & $94,4 \%$ \\
\hline Sensitivitas & $=\frac{\mathrm{a}}{\mathrm{a}+\mathrm{c}} \quad \mathrm{X} 100 \%=$ & $\frac{11}{12} \times 100 \%=$ & $91,7 \%$ \\
\hline Spesifisitas & $=\frac{\mathrm{d}}{\mathrm{b}+\mathrm{d}} \quad \mathrm{X} \quad 100 \%=$ & $\frac{23}{24} \times 100 \%=$ & $95,8 \%$ \\
\hline Nilai Ramal positif & $=\frac{a}{a+b} \quad \times \quad 100 \%=$ & $\frac{11}{12} \times 100 \%=$ & $91,7 \%$ \\
\hline Nilai Ramal negatif & $=\frac{d}{c+d} \quad X \quad 100 \%=$ & $\frac{23}{24} \times 100 \%=$ & $95,8 \%$ \\
\hline Rasio Kemungkinan positif & $=\frac{\text { sensitivitas }}{(1-\text { spesifisitas })}=$ & $\frac{0,9166}{0,0417}$ & 21,9 \\
\hline Rasio Kemungkinan negatif & $=\frac{(1-\text { sensitivitas })}{\text { spesifisitas }}=$ & $\frac{0,083}{0,9545}=$ & 0,087 \\
\hline Pretest probability & $=\frac{a+c}{a+b+c+d} \times 100 \%=$ & $\frac{12}{36} \times 100 \%=$ & $33,33 \%$ \\
\hline Pretest odds & $=\frac{\text { Prevalence } 0,3333}{(1-\text { Prevalence }) 0,6667}$ & & $0,499 \%$ \\
\hline Post test odds & $\begin{array}{l}=\text { Pretest odss } \times \text { Rasio Ke } \\
=\text { Pretest odss } \times \text { Rasio Ke1 }\end{array}$ & $\begin{array}{l}\text { emungkinan Pos } \\
\text { emungkinan Neg }\end{array}$ & $\begin{array}{l}\text { itif }=0,499 \times 21,9=10,93 \\
\text { atif }=0,499 \times 0,087=0,043\end{array}$ \\
\hline Post test probability odds & $=\frac{\text { Post test odds }}{(\text { Post test odds }+1)}=$ & $\begin{array}{l}\frac{10,93}{11,93}=0,910 \\
\frac{0,043}{1,043}=0,04\end{array}$ & \\
\hline
\end{tabular}


mempunyai hasil pemeriksaan BAJAH positif terhadap adanya keganasan pada limfadenopati koli.

Dalam penelitian ini dijumpai 1 penderita dengan hasil negatif palsu dari pemeriksaan BAJAH didiagnosis sebagai limfadenitis kronis non sepesifik tetapi hasil pemeriksaan histopatologinya suatu metastasis karsinoma sel skuamosa. Pada penderita ini kemungkinan negatif palsu tersebut kemungkinan karena jarum aspirasi mengenai daerah nekrosis. Dari sediaan biopsi secara mikroskopik terdapat sarang-sarang jaringan nekrotik yang cukup luas. Dari kepustakaan dikatakan salah satu penyebab positif atau negatif palsu adalah adanya daerah nekrosis. ${ }^{17}$

Pada penelitian ini dijumpai 1 penderita dengan hasil positif palsu, dari pemeriksaan BAJAH didiagnosis non Hodgkin limfoma tetapi pada pemeriksaan histopatologis ternyata suatu hiperplasia reaktif. Hal ini disebabkan kemungkinan karena campuran populasi sel pada non Hodgkin limfoma juga ada pada reaktif hiperplasia. Beberapa kepustakaan menyebutkan bahwa sulit untuk membedakan suatu non Hodgkin limfoma dengan hiperplasia reaktif dengan teknik BAJAH sehingga harus dilakukan pemeriksaan penunjang lain misalnya dengan pemeriksaan immunohistokimia. ${ }^{14,15}$

Dari kepustakaan disebutkan bahwa hiperplasia reaktif, fibrosis, hanya sebagian dari kelenjar getah bening (KGB) yang mengandung massa tumor, sampel tidak adekuat, dan kesalahan interpretasi merupakan penyebab adanya kesalahan diagnosis pada kasus limfoma maligna. ${ }^{23}$

Salah satu penderita didiagnosis dengan pemeriksaan BAJAH sebagai suatu metastasis karsinoma KGB tidak berdiferensiasi ternyata hasil histopatologinya suatu Hodgkin limfoma. Penegakan diagnosis Hodgkin limfoma pada kasus ini berdasarkan adanya variasi gambaran sel Reed Sternberg yaitu sel dengan inti multiple mummified. Perbedaan diagnosis ini kemungkinan karena sel Reed Sternberg tersebut tidak terambil pada saat pengambilan sampel BAJAH. Hal ini dimungkinkan karena sel Reed Sternberg populasinya sangat sedikit yaitu hanya $2 \%$ dari populasi tumor. ${ }^{14}$

Pada penelitian ini juga dijumpai salah satu penderita dengan pemeriksaan BAJAH yang didiagnosis sebagai Hodgkin limfoma tetapi pada pemeriksaan histopatologis hasilnya non Hodgkin limfoma. Pada kasus ini dari pemeriksaan BAJAH ditemukan sel ukuran sedang, poligonal, inti sel besar, sitoplasma sedikit inti melekuk, binukleated, dan beberapa sel inflamasi seperti limfosit, dan sel polimorfonuklear (PMN). Dari kepustakaan disebutkan bahwa sel yang menyerupai sel Reed Sternberg, juga dapat ditemukan pada penyakit lain diantaranya beberapa jenis non Hodgkin limfoma, tumor jaringan ikat, dan beberapa jenis infeksi. ${ }^{15,23}$ Untuk membantu menegakkan diagnosis pada kasus ini perlu dilakukan pemeriksaan immunohistokimia.

Dari penelitian ini didapatkan suatu hasil metastasis karsinoma secara patologi yang merupakan kasus kedua terbanyak setelah tuberkulosis yaitu $10(27,8 \%)$ penderita.
Sedangkan hasil pemeriksaan BAJAH didapatkan hanya 1 penderita yang didiagnosis sebagai metastasis karsinoma, jadi tidak sesuai dengan hasil pemeriksaan histopatologis, sedangkan sisanya sesuai dengan pemeriksaan histopatologis. Dari kepustakaan pemeriksaan BAJAH mempunyai akurasi yang tinggi yaitu diatas $95 \%$ dalam mendiagnosis metastasis karsinoma pada penderita dengan limfadenopati koli.?

Pada kasus limfadenopati koli tuberkulosis didapatkan hasil pemeriksaan BAJAH semuanya identik dengan hasil pemeriksaan histopatologis, angka sensitivitas $100 \%$ dan spesifisitas $100 \%$. Penelitian yang dilakukan Nazar Hussain dan Naveed ${ }^{24}$ mendapatkan angka sensitivitas $100 \%$ dan spesifisitas 98\%. Dengan demikian pemeriksaan BAJAH mempunyai akurasi yang tinggi untuk mendiagnosis limfadenopati koli yang disebabkan adanya infeksi tuberkulosis.

\section{SIMPULAN}

Berdasarkan analisis dan pembahasan penelitian ini dapat disimpulkan angka akurasi pemeriksaan BAJAH dalam mendiagnosis suatu keganasan pada penderita limfadenopati koli tinggi yakni $94,4 \%$, dengan sensitifitas $91,7 \%$, spesifisitas $95,8 \%$, nilai ramal positif $91,7 \%$, dan nilai ramal negatif adalah $95,8 \%$. Pemeriksaan BAJAH dapat digunakan secara rutin untuk mendiagnosis adanya keganasan pada penderita limfadenopati koli terutama untuk penderita yang tidak memungkinkan untuk dilakukan biopsi terbuka.

\section{DAFTAR PUSTAKA}

1. Moeslichan S. Pencegahan dan deteksi dini penyakit kanker. Jakarta: Perkumpulan Onkologi Indonesia; 1994.

2. Ioachim HL. Metastatic tumors in lymph nodes. Lymph node pathology. 2nd ed. Philadelpia: JB Lippincot Company; 1993.

3. Powl D. Tuberculosis lymphadenitis in tuberculosis infectious desease. New York: Schlossberg Ded. Praegoer Publisches; 1993.

4. Anderson JT. Head \& neck tumors. California: Departement of Surgery Division of Trauma \& Emergency Surgery; 2006.

5. Mayer JS. Greenfield's surgery scientific principles \& practice. 4th ed. New York: Lippincot Williams \& Wilkins: 2006.

6. Izhar NB, Shubada V, Roshni F, Cytologic evaluation of enlarged neck node: FNAC utility in metastatic neck disease. J Pathol [serial on the internet]. 2007 [cited 2008 Jun 23];6:1-9. Available from : http//www.ispub.com/ostia/index. php?xmlFilePath=journals/ijpa/vol6n2/neck.xml

7. Orell SR, Sterrett GF, Withaker D. Fine needle aspiration cytology. 4th ed. Australia: Elsevier Churchill Livingstone; 2003.

8. Roskell, Buley. Fine needle aspiration cytology in cancer diagnosis. BMJ J [serial on the internet]. 2004 [cited 2008 Jul 22]; 329:1-3. Available from http://bmj.bmjjournals.com/www. pubmedcentral.nih.gov/articlender.fcgi?artid=498011

9. Mahfuzh F, Soerjadi KS, Darnita F, Rusmajono. Limfadenitis tuberkulosis leher. Jakarta: Bagian THT FKUI: 1993.

10. Dong GN, Nyo KL, Hong SB. Hong SK, Youn HK. Cervical lymphadenophaty: usefullness of color doppler sonografi. AJR. 1997; 168:1311-6. 
11. Choi MY, Lee JW, Jang KS. Distinction between benign and malignat causes of cervical, axillary and inguinal lymphadenophaty. Value of doppler spectral waveform analysis. AJR. 1995; 165:981-4.

12. Semiarti E, Makes D, Poetiray EDC. Ketepatan pemeriksaan sonografi doppler berwarna pada limfadenopati leher. Jakarta: Bagian Radiologi FKUI: 2000.

13. Alwan NA. Fine needle aspiration cytology versus histopathology in diagnosing lymph node lesions. East Mediterr Health J. 1996; 2(2):320-6.

14. Rosai J. Rosai and Ackerman's surgical pathology. 8th ed. Missouri: Mosby Year Book; 1996. p. 1661-773.

15. Koss LG. Lymph nodes: Koss' diagnostic cytology and its histopathologic bases. In : Nancy PC, Ruth LK, editors. Lymp nodes. 5th ed. Philadelphia: Lippincott Williams \& Wilkins: 2006. p. 1187-19.

16. Gupta RK. The Diagnostic value of fine needle aspiration cytology (FNAC) in the assessment of palpable supraclavicular lymph nodes. Cytopathology: 2003; 14:201-7.

17. Johnson T. Fine needle aspiration of neck masses. eMedicine $\mathrm{J}$ [serial on the Internet]. 2008 [cited 2008 Jul 22]; 4-8. Available from : http://www.emedicine.com/ent/TOPIC561.HTM

18. Bagwan IN, Shubada V, Roshni. Chinoy. Cytologic evaluation of enlarged neck node: FNAC utility in metastatic neck desease. Intern J Pathol. 2007; 2:1-2.

19. Tanwir YM. Teknik pengelolaan sediaan histopatologi dan sitologi. Bandung: Lab/Instalasi Patologi Anatomi FK Unpad: 1989.

20. James L. Development of needle aspiration technique, in thin needle aspiration biopsy. Philadelphia: W.B Saunder company; 1983.

21. Dahlan MS. Besar sampel dalam penelitian kedokteran dan kesehatan. Seri Evidence Based Medicine. Jakarta: PT ARKANS; 2006.

22. Javaid M, Said M. Diagnostic value of fine needle aspiration cytology (FNAC) in cervical lymphadenophaty. J Posgrad Med Inst, Pesawar: Hayatabad Medical Complex, and Leady Reading Hospital. 2006; 20(2): 117-20.

23. Steel BL, Schwartz MR, Ramzy I. Fine needle aspiration biopsy in the diagnosis of lymphadenopathy in 1,103 patients. Role, limitations and analysis of diagnostic pitfalls. Department of Pathology, Baylor College of Medicine : Texas. Acta Cytol. 1995; 39(1):76-81.

24. Hussain N, Naveed IA, The value of needle aspiration cytology in the diagnosis of lymphadenophaty, Biomedica: 2002; 18:3840 . 